\title{
Ethnicity at the Individual and Neighborhood Level as an Explanation for Moving Out of the Neighborhood
}

\author{
Karina Schaake $\cdot$ Jack Burgers $\cdot$ Clara H. Mulder
}

Received: 25 December 2008/ Accepted: 13 October 2009/Published online: 6 November 2009

(C) The Author(s) 2009. This article is published with open access at Springerlink.com

\begin{abstract}
We address the influence of both the ethnic composition of the neighborhood and the ethnicity of individual residents on moving out of neighborhoods in the Netherlands. Using the Housing Research Netherlands survey and multinomial logistic regression analyses of moving out versus not moving or moving within the neighborhood, we found that ethnicity at the individual level was not of much importance for moving out. The combination of ethnicity at the individual level and the neighborhood level, however, appeared to be a rather important explanation of geographical mobility. Ethnic minorities are more likely than native Dutch to move within neighborhoods, and less likely to move away from them, as the share of nonwestern minorities in those neighborhoods increases. Native Dutch move away more frequently than ethnic minorities as the share of non-western ethnic minorities in neighborhoods is greater. These results suggest ethnic enclave formation or place stratification in the Netherlands.
\end{abstract}

K. Schaake $(\bowtie) \cdot$ J. Burgers

Faculty of Social Sciences, Department of Sociology, Erasmus University Rotterdam,

P.O. Box 1738, 3000 DR Rotterdam, The Netherlands

e-mail: schaake@fsw.eur.nl

J. Burgers

e-mail: burgers@fsw.eur.nl

K. Schaake

Amsterdam School for Social science Research (ASSR),

Kloveniersburgwal 48, 1012 CX Amsterdam, The Netherlands

C. H. Mulder

Department of Geography, Planning and International Development Studies,

University of Amsterdam, Nieuwe Prinsengracht 130,

$1018 \mathrm{VZ}$ Amsterdam, The Netherlands

e-mail: c.h.mulder@uva.nl 
Keywords Ethnicity - Neighborhood - Residential mobility · Migration ·

Segregation · Logistic regression · The Netherlands

\section{Introduction}

Residential mobility of middle class residents out of ethnic minority concentration areas is a familiar phenomenon in both US and European cities. Originally, these middle class residents were mainly whites, but middle class members of minority groups are increasingly showing a similar pattern of residential mobility. Wilson (1987, 1996), for instance, has shown how the traditional American inner-city black ghetto turned into a 'hyper ghetto' because middle class African Americans were able to move out in the latter half of the twentieth century. The people staying behind in those increasingly deprived areas were likely to stay there for a long time (Quillian 2003), because many of them simply could not afford to leave (Bolt and Van Kempen 2003). Those who were able to move out usually suburbanized (see e.g. Alba and Logan 1991, 1993; Alba et al. 1999; Galster 1991; Gross and Massey 1991; Logan et al. 1996; Massey and Denton 1985; Mieszkowski and Mills 1993; Palen 1995; Schneider and Phelan 1993; South and Crowder 1997b).

In Western Europe, 'black flight'-middle class members of ethnic minorities leaving ethnically segregated neighborhoods-is a rather new phenomenon. This is mainly due to the relatively short immigration history of many West-European countries, because of which social mobility of members of minority groups is a fairly recent development. For the Netherlands, previous research on residential preferences and mobility of middle class members of minority groups (e.g. Burgers and Van der Lugt 2006; De Groot 2004; Uyterlinde et al. 2007) seems to indicate that the rising socio-economic status of parts of these ethnic minority groups leads to a convergence of their residential patterns with those of the native Dutch, resulting in 'black flight'. The available research for the Netherlands, however, mainly has an explorative character and consists of predominantly small-scale local and qualitative studies. And although ethnicity of individual residents has been a factor in analyzing residential mobility and migration in urban contexts-mainly Amsterdam and Rotterdam (De Groot 2004; Burgers and Van der Lugt 2006) - the combined effects of both ethnicity of individuals and ethnic composition of neighborhoods on residential mobility have not yet been assessed.

In this article we address the influence of both the ethnic composition of the neighborhood and the ethnicity of individual residents on moving out of neighborhoods in municipalities in the Netherlands, using the Housing Research Netherlands survey. Our analysis was inspired by the recent study of Pais et al.'s (2009), who took both individual ethnicity and ethnic composition of the neighborhood into account in their analysis of moving out of American neighborhoods. In this contribution, we address two basic questions: What is the role of ethnic composition of the neighborhood in explaining moving out of neighborhoods? And what is the role of the ethnicity of individual residents in this respect? The answers to these two questions make it possible to assess to what degree different ethnic groups move away from each other. 


\section{Theoretical and Research Background}

\section{Three Theoretical Positions}

In theories and research on residential mobility and migration, ethnicity is an important factor. The main question in these theories is whether differences in residential behavior among ethnic groups are caused by financial constraints, by barriers in the housing market or by cultural differences. These three possibilities represent three different theoretical positions.

First, there is the spatial assimilation theory which claims that ethnic minority groups will eventually 'assimilate' to the mainstream culture of the country they reside in. Ethnic minorities will follow whites in their (mostly suburban) moves as they 'acculturate' and move up on the socio-economic ladder, and thus there will eventually be both 'white' and 'black flight' (Gross and Massey 1991; Massey 1985; Massey and Denton 1985). Differences among various ethnic groups are conceived of as basically temporary in nature, that is, dependent on upward social mobility and available financial resources (Alba and Logan 1991, 1993; Burgers and Van der Lugt 2006; Massey and Mullan 1984; Van der Zwaard 2005).

The second theoretical position starts from the same point of departure as the spatial assimilation theory in that it also presupposes that minority groups have the tendency or willingness to assimilate. But it differs from the first in that, apart from financial barriers, it stresses various structural barriers (such as discrimination on the housing market or housing policies) that block the realization of aspirations and, thus, the (spatial) assimilation of these groups. This model, focusing on structural limitations for ethnic or racial minorities when it comes to residential mobility, has become known as the 'place stratification model' (Logan and Molotch 1987). Using this model, South and Crowder (1997a) have shown that it is easier for African Americans to move into concentrated areas than into non-concentrated areas and that white Americans often want to leave concentrated areas precisely because of their ethnic minority concentration. According to this model, residential mobility among ethnic minorities is limited (in the US mainly for African Americans), especially out of concentrated areas (similar outcomes were shown by e.g. Aalbers 2006; Aalbers and Deurloo 2003; Bolt and Van Kempen 2003; South and Crowder 1998; Uitermark and Duyvendak 2004).

The third theoretical scheme is the 'ethnic enclave' model (Portes and Jensen 1987). This model argues that ethnic minorities tend to cluster, usually in poor urban areas, immediately after arrival in the country of destination. Zhou and Logan (1991) point out that this ethnic concentration is at first more or less inevitable but later becomes increasingly seen as an asset by both its residents and newly arriving migrants because of the amenities and organizations feeding on this ethnic concentration. That is why residents stay in these enclaves even when they have the financial means to move out. Other members of minority groups from outside the neighborhood may even move in voluntarily (cf. Massey 1985; Van Huis and Nicolaas 2000). According to the ethnic enclave model, ethnic minorities prefer to live in an ethnic minority concentration area despite the lower quality of dwellings 
in these areas in order to live with people with the same ethnic background and to live close to specific ethnic amenities.

\section{Research Design and Hypotheses}

In spite of the attention paid to ethnicity in the various theoretical models on residential mobility, not much is known about people from various ethnic origins leaving neighborhoods because of the ethnic composition of the neighborhood. In the cases in which ethnicity was included as an explanatory factor for residential mobility or migration, in most cases it turned out that socio-economic factors, and not so much ethnicity, played a key role. Jego and Roehner (2006), for example, have shown that 'white flight' in the US was actually a flight from poor neighborhoods, and not so much a flight from ethnic minorities or blacks. Harris (2001) has stressed the same point when he explained the flight from ethnic minorities by using the racial proxy hypothesis. At a closer look, the ethnic/racial composition of the neighborhood proved to be a proxy for concentration of social problems which caused in fact both 'white' and 'black flight'.

Recently, Pais et al. (2009), however, did find an influence of the ethnic and racial composition of a neighborhood on moving out of the neighborhood. Various ethnic groups displayed different patterns in this respect. Whites tended to move out of neighborhoods with ethnic minority concentrations. Mexicans and Puerto Ricans, on the other hand, were likely to leave white neighborhoods. African Americans' decisions to move out seemed to be barely influenced by the ethno-racial composition of the neighborhood. Although inspired by Pais et al. (2009) study, our analysis differs from it in three important respects.

First, we focus on ethnicity in a different institutional setting, the Netherlands. One of the peculiarities of the Dutch welfare-state is that a substantial part of the housing stock is provided by non-profit organizations. About $75 \%$ of the rental housing stock is social housing, which amounts to almost a quarter of all housing in the Netherlands.

Second, we distinguish between ethnicity and socio-economic status and introduce interaction terms between the two of them and neighborhoods' ethnic composition. Especially in the Dutch case, it has been extremely difficult in the recent past to distinguish between socio-economic status and ethnicity. The overwhelming majority of members of minority groups had a low socio-economic status. Now that there are clear tendencies towards upward social mobility within migrant communities (Burgers and Van der Lugt 2006; Dagevos and Gijsberts 2005; Gowricharn 2001, 2003; Van der Horst and Wassenberg 2004; Van Niekerk 2000), these groups have become more heterogeneous in terms of income and educational level, and therefore it is now possible to differentiate statistically between ethnicity and socio-economic status.

Third, instead of analyzing mobility in the form of a dichotomy-moving out or not-as Pais et al. (2009) have done, we focus on three different forms of mobility: moving out of the neighborhood, moving within the neighborhood, and not moving at all. Thus we specify residential mobility, and increase the accuracy of our analysis, possibly resulting in different effects from those mentioned by Pais et al. 
(2009). Reasons for staying in the neighborhood may be very different for people who do not move at all and people who do move but do so within their neighborhood, which makes categorizing them as just one group rather problematic. At the same time, we also cannot ignore people who did not move at all and focus only on people who moved, because the category of movers is selective.

When it comes to the role of ethnicity, we aim to explain moving out of neighborhoods, focusing on both the ethnic background of individuals and the ethnic composition of the neighborhood. Building upon the theoretical positions described above, our analysis is guided by three hypotheses.

In line with spatial assimilation theory, we expect that the higher the percentage of ethnic minorities in a neighborhood, the more moves there will be out of the neighborhood (hypothesis 1). Not only will native Dutch move out of neighborhoods with high percentages of ethnic minorities if they can, but so will members of minority groups if they have the means to do so. This, however, is expected to hold more for native Dutch than for members of minority groups (hypothesis 2). This could be true for reasons in line with all three theoretical models. Native Dutch could be in a better financial position than ethnic minorities; members of minority groups could face discriminatory practices which block their opportunities to move out in spite of the availability of financial means to move out; or native Dutch and ethnic minorities may tend to avoid each other. Therefore, if hypothesis 2 holds, we then control for socioeconomic status. If the assimilation model is correct, we expect the difference between native Dutch and members of minority groups to disappear (hypothesis 3a). In case the place stratification model or the ethnic enclave model is correct, the difference will persist (hypothesis 3b). Our data do not permit us to decide between the place stratification model and the ethnic enclave model.

It could be argued that, if we had data on changes in housing prices, the opportunities for distinguishing between the place stratification model and the ethnic enclave model would be better. In the economic literature, it has been argued that housing prices react to residential moves of people from different ethnic backgrounds in different ways depending on the preferences of ethnic groups for living near co-ethnics (see for example Card et al. 2008; Cutler and Glaeser 1997). In neighborhoods from which many native Dutch leave, prices would fall if the place stratification model would hold (because the neighborhood would become less attractive to native Dutch) but stay the same, or rise temporarily, if the ethnic enclave model would hold (because the neighborhood would become more attractive to ethnic minorities). We do not have data on changes in housing prices. Moreover, in the Dutch case it is less convincing that prices would react to changes in ethnic neighborhood composition that much, if at all, because the proportion of social housing with regulated prices is high precisely in neighborhoods with high percentages of ethnic minorities.

In assessing the role of ethnicity in explaining moving out of the neighborhood, we have to control for variables known to be important to both the occurrence and direction of geographical mobility. First of all, it is important to account for socioeconomic status. In many cases, the ability to move is conditioned by the availability of the necessary financial means (cf. Deane 1990). Besides income, 
level of education is important (cf. Fernandez et al. 2007). To be able to isolate the effect of the ethnic composition of a neighborhood from the effect of its degree of socio-economic deprivation, we also take the socio-economic deprivation of the neighborhood into account.

Other factors we have to take into account are basically demographic in character and related to phase in the life course. Households move in response to (changes in) household size and age (Rossi 1955; Mulder 1993; Zorlu and Mulder 2008). The housing situation before a potential move is also important. Residential crowding, usually measured as number of persons per room, has been shown to increase the likelihood of moving (Clark et al. 2000). Home ownership can tie people to their actual residence, and therefore home owners are less likely to move than renters (Helderman et al. 2006; McHugh et al. 1990; South and Crowder 1998; Speare 1974).

\section{Data and Methods}

Sample

In order to test our hypotheses, we combined three datasets in our analyses. The main dataset is the Housing Research Netherlands 2006 (HRN, Dutch acronym WoON 2006), a dataset of the Dutch Ministry of Housing, Spatial Planning and Environment (VROM 2006) which is based on a survey conducted between September 2005 and March 2006. HRN is based on a representative sample of the population of the Netherlands, aged 18 and over not living in institutions, and contains information on housing and related issues. We added 2006 ethnicity data for postal codes to this dataset, obtained from Statistics Netherlands, as well as postal code socio-economic deprivation data from the SCP (Social and Cultural Planning Office) Status Score dataset.

As we aimed at heads of households and their partners-after all, they are the ones to decide whether or not to move-we only included these in our analyses, thereby decreasing the total number of respondents from 64,005 to 55,958 . The dependent variable had missing values for 881 respondents. Of the remaining 55,077 respondents, 52,873 $(96.0 \%)$ had valid outcomes on all independent variables and were included in our analyses.

\section{Variables}

The dependent variable has three values: did not move at all, moved within the postal code area, and moved out of the postal code area. We based this variable on mobility data in HRN 2006 for which respondents were asked when they came to live at their current address. If that occurred within the 2 years prior to the interview, they were denoted as 'moved'. Because respondents were asked for their postal codes of their earlier address, they could be distinguished as either "moved within postal code area" or "moved out of postal code area". All other respondents 
were denoted as "did not move". The average number of addresses per postal code in the Netherlands is 1,793 , and postal codes provide a good approximation of the neighborhood level.

The two main independent variables used in order to test our hypotheses are (1) ethnicity of the respondent and (2) non-western minority percentage in the postal code area. The respondent's ethnicity was categorized into native Dutch, Caribbean (Surinamese or Antillean), Turkish, Moroccan (these latter three groups are the largest ethnic minority groups in the Netherlands), other non-western minorities, and western minorities, following the official definition of Statistics Netherlands. ${ }^{1}$ We created the second main independent variable by computing the continuous variable of the total number of non-western minority residents per postal code, as a percentage of the total number of people per postal code, using 2006 data from CBS (Statistics Netherlands).

We controlled for several individual socio-economic and demographic variables, housing variables, and postal code area variables. The number of children is a continuous variable. Having a partner is a dichotomous variable with no partner as the reference category. Age and age squared were measured in years, and sex is dichotomous (male $=0$, female $=1$ ). The first individual socio-economic variable is household income measured in 1,000s of Euros per year before taxation. We corrected for outliers: incomes below 0 or above 200,000 Euros were recoded as 0 Euros (114 cases, which is $0.2 \%$ of the sample) or 200,000 Euros per year (244 cases, which is $0.5 \%$ of the sample). The second socio-economic variable is highest completed level of education. We measured this variable in three categories: up to lower secondary school (reference category); middle or higher secondary school or lower professional education; higher professional education or university. Residential crowding was measured as the number of persons occupying the dwelling divided by the number of rooms. Home ownership was measured as owner-occupied (1) versus renter (0).

The socio-economic deprivation of the postal code area was created by SCP (Social and Cultural Planning Office), and is a composite measure for 2006 of the area's average household income (the higher the average income, the lower the deprivation score), the percentage of those with low incomes, the percentage unemployed, and the percentage of those with a low level of education. The original scores were divided by 100 to obtain better readable parameters.

\footnotetext{
${ }^{1}$ In the Netherlands, ethnicity is officially defined by the country of origin of the individual and her/his parents. The Dutch government makes the following distinction: if both parents were born in the Netherlands, the individual is seen as native Dutch, even if the individual her/himself was born outside the Netherlands. If the individual and one or both parents were born outside the Netherlands, the ethnicity of the individual refers to that country. If the individual was born in the Netherlands and one or both parents were born outside the Netherlands, the ethnicity of the individual is that of the country of origin of the parent born outside the Netherlands, with the addition of belonging to the 'second generation'. The distinction between western and non-western origin mainly depends on the continent someone/someone's parents were born in. Africa, Latin-America, and most of Asia (including Turkey) are considered nonwestern. All other countries, including Indonesia (a former Dutch colony) and Japan, are considered western.
} 
Analysis

We used multinomial logistic regression analyses to test our hypotheses. We present three models. The first model contains the main effects of all independent variables. This model allows us to test hypothesis 1 . In the second model, the interaction between individual ethnicity and the ethnicity of the neighborhood is also included to allow for testing hypothesis 2. In the third model, the interaction between household income and the ethnicity of the neighborhood is added to allow for evaluating hypotheses $3 \mathrm{a}$ and $3 \mathrm{~b}$.

To prevent the standard errors from being affected by the clustering of respondents in postal codes, we have adjusted the standard errors for this clustering by means of the Huber-White sandwich estimator (Huber 1967).

\section{Results}

\section{Descriptive Statistics}

Table 1 presents descriptive statistics of the variables used in our analyses. Native Dutch move the least, followed by western minorities. Moving within the neighborhood does not show major differences among ethnic groups. Opposite to what one might expect based on socio-economic background by ethnic group, Caribbeans and other non-westerners, and not native Dutch, have the highest rate of moving out of neighborhoods.

As for demographic characteristics, native Dutch are older than the other ethnic groups. This is in line with the general demographic picture of the Netherlands, where ethnic minorities have entered the Netherlands since the 1970s at young ages and have thus not yet reached older ages, and they have more children and are thus younger on average. Turks are living with a partner more frequently than the other groups, closely followed by Moroccans and native Dutch. Caribbeans have the highest proportion of people living without a partner. Native Dutch have fewer children than all non-western ethnic groups.

Educational level is highest for western minorities and, maybe surprisingly, the second highest for the group of other non-western minorities. There may be two reasons for this finding. An important part of the other non-western immigrants might be 'knowledge workers'. Another part might consist of highly skilled asylum migrants.

As we would expect, the mean household income of native Dutch and western minorities is much higher than that of Moroccans, Turks, Caribbeans and other nonwestern minorities. Native Dutch also show a higher home ownership rate than the other ethnic groups.

The Influence of Ethnicity at the Individual and Neighborhood Level

Table 2 shows the results of the multinomial logistic regression analysis. Model 1 shows that, in line with hypothesis 1 , the proportion of ethnic minorities in a postal 


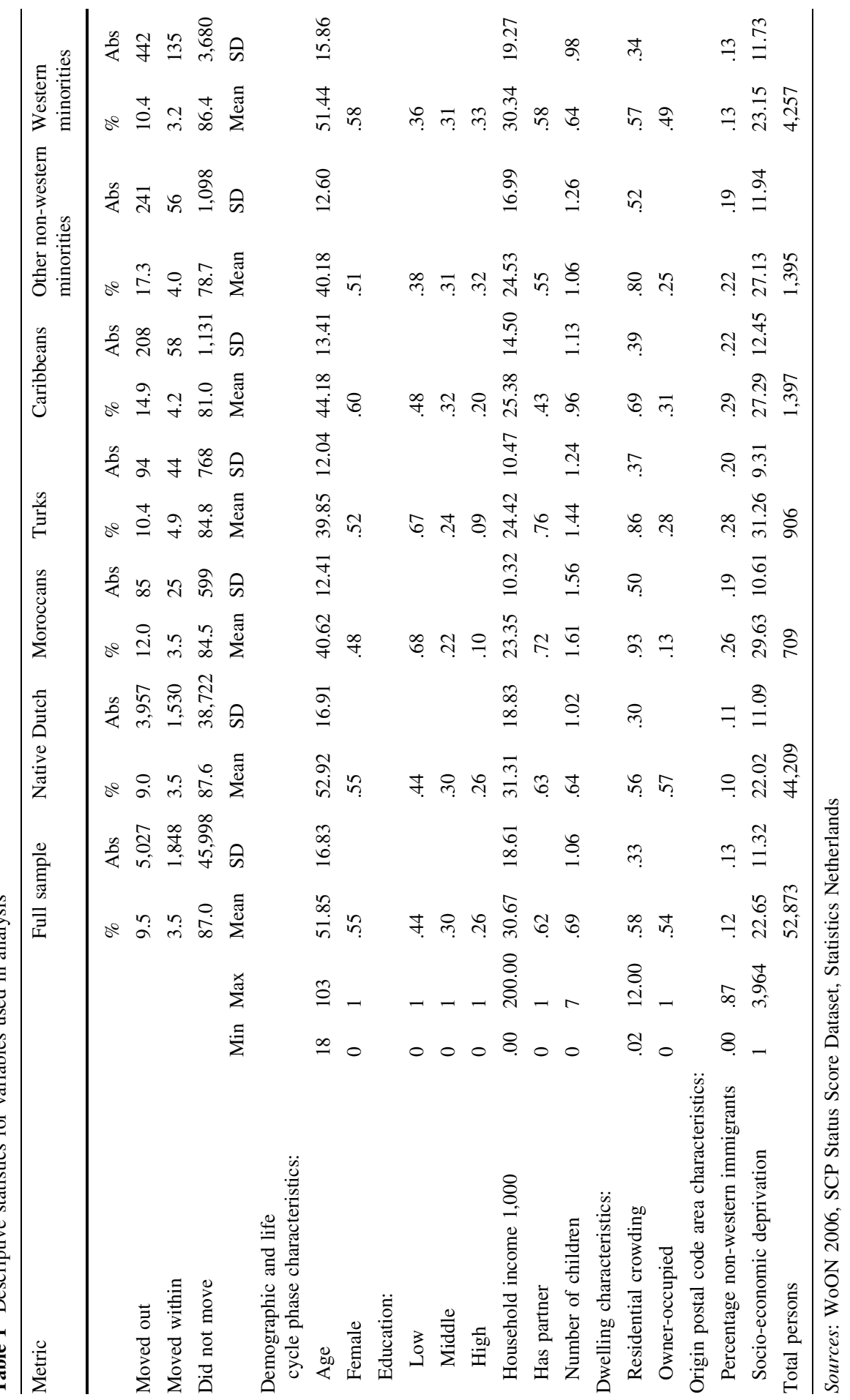




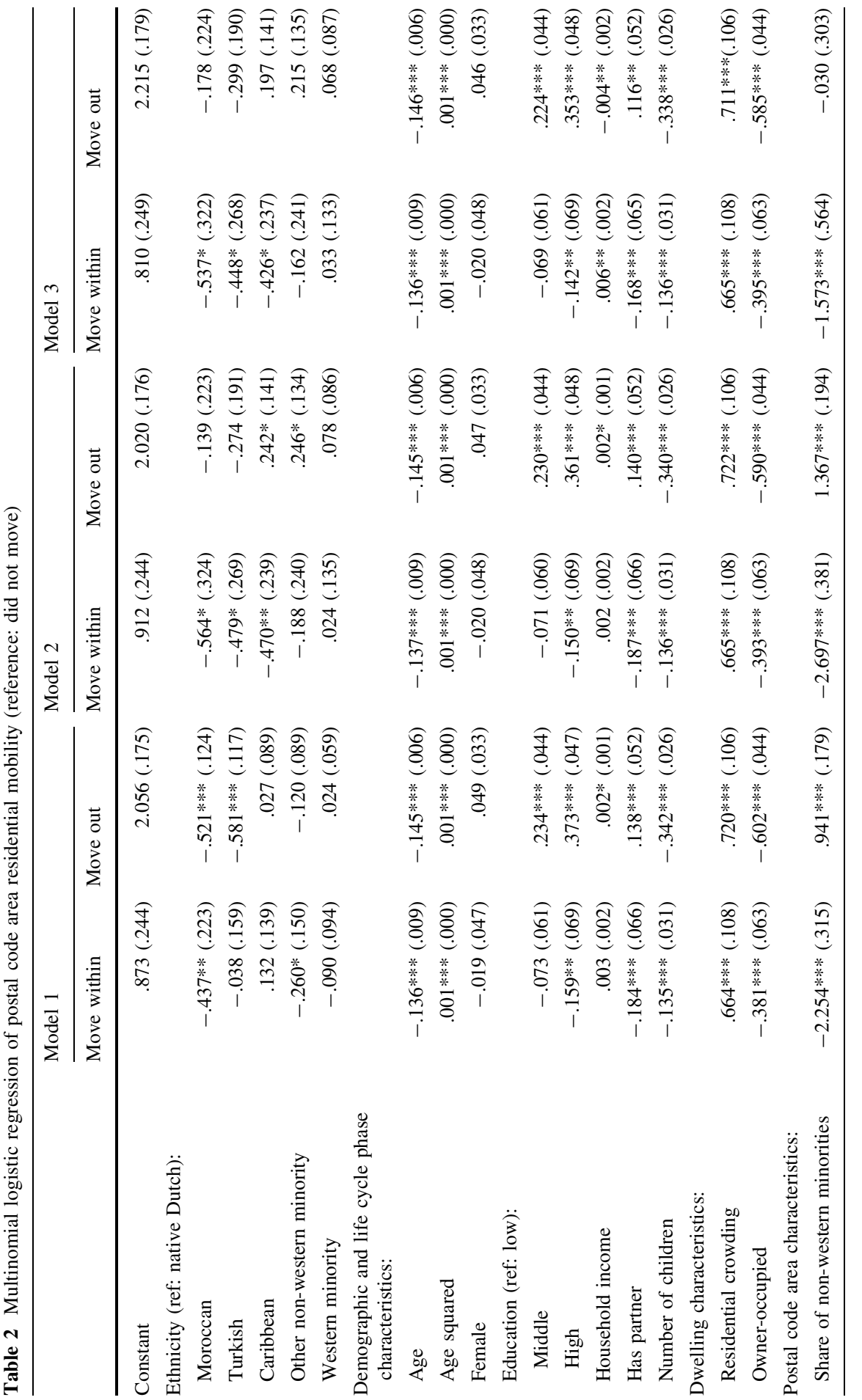




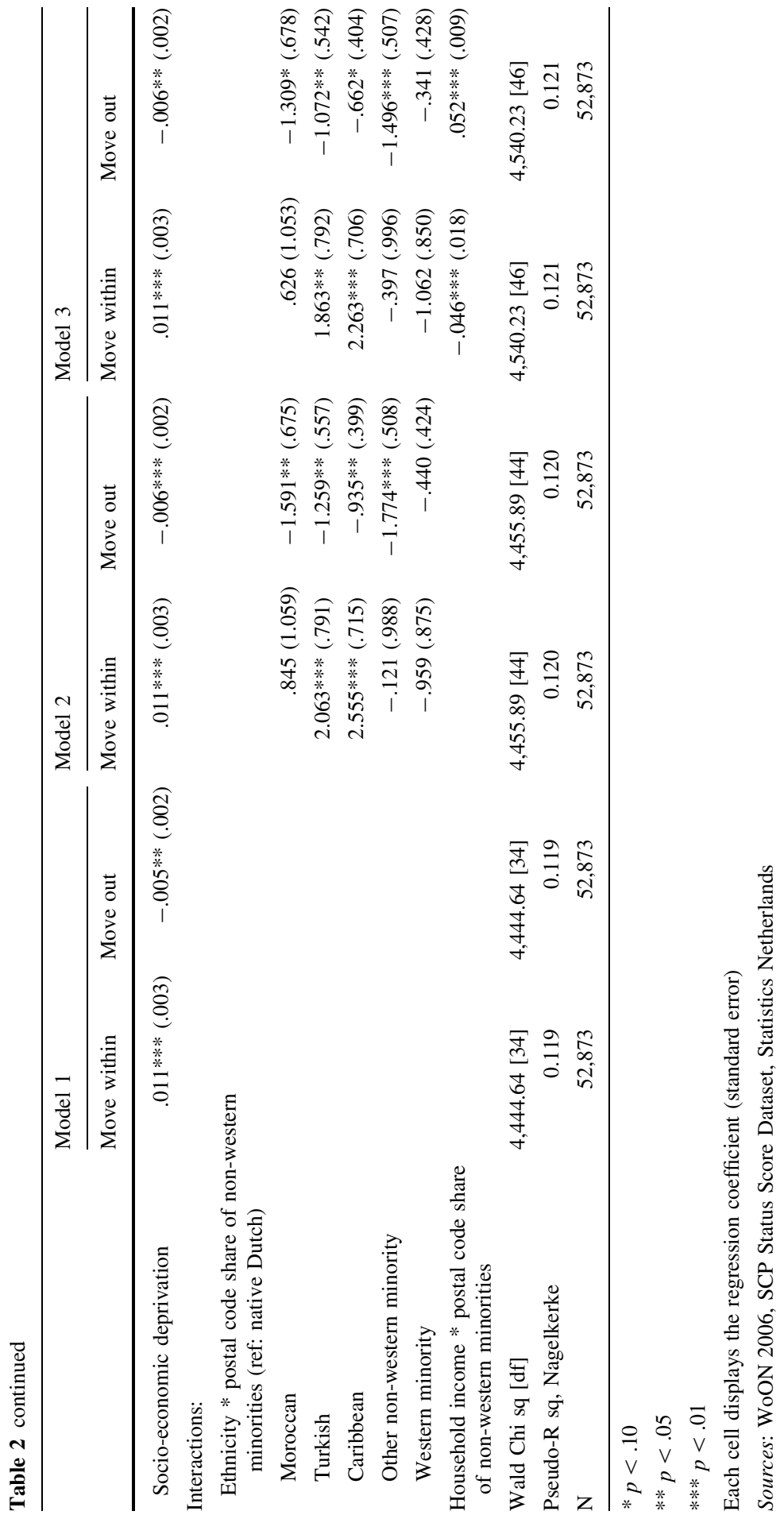


code area has a positive effect on moving out and a negative effect on moving within the postal code area. Neighborhoods with a high share of ethnic minorities are in general less attractive and generally offer less favorable life chances than other neighborhoods (cf. Logan and Molotch 1987). One would therefore expect that, if possible, inhabitants of such neighborhoods would move out of rather than move within their neighborhoods. Hence, the positive effect of neighborhood ethnicity on moving out and the negative effect on moving within a neighborhood are no surprise. This finding might reflect a more general pattern in the sense that some factors that have a positive influence on moving out of a neighborhood might be negatively associated with moving within the neighborhood. One would expect this to be the case particularly if a certain factor is associated with the attractiveness of neighborhoods but not with the likelihood of moving in general. In such cases, there might be a fixed number of movers, and the fact that a disproportionately great share of these movers leave the neighborhood automatically leads to a small share moving within the neighborhood.

After controlling for the other independent variables, certain ethnic groups show specific mobility patterns. Moroccans move less frequently than native Dutch, both within the neighborhood and out of the neighborhood. As individual socioeconomic status has been controlled for, this might mean that Moroccans have a lower propensity to move at all, even if they have the financial means to do so. Turks also move out of their postal code area less frequently than native Dutch. Other nonwestern ethnic minorities move less within their postal code area than native Dutch.

The socio-economic deprivation of a postal code area shows a significant positive influence on moving within the postal code area and a negative influence on moving out of the postal code area. It should be borne in mind, though, that this effect is estimated after controlling for the effect of neighborhood ethnicity. In fact in a model in which neighborhood ethnicity was not included (not shown), the effect of neighborhood deprivation was insignificant. Our result might indicate that it is not so much socio-economic deprivation people move away from (or stay close to), but the ethnic composition of their neighborhoods. Given this ethnic composition, they may stay in deprived areas in which the percentage of non-western minorities is lower than usual or move from less deprived areas in which it is higher than usual.

Household income is also not found to be a predictor of moving within the area. It does, however, have a positive effect on moving out of the area. Having a partner is negatively related to moving within the area, whereas it is positively related to moving out of the area. The number of children, however, influences moving both within and out of the area negatively. ${ }^{2}$ A high level of education is negatively related to moving within the postal code area, whereas it is positively related to moving out of the area. A middle educational level also has a positive influence on moving out of the neighborhood. The effects of age and age squared are similar for moving within and out of the postal code area. The age effect is estimated to be Ushaped, with the minimum around age 70. As expected, home owners are less likely

\footnotetext{
2 As the number of children is highly skewed, we conducted the same analysis with the number of children categorized into $0,1,2$, or 3 or more, and log-transformed. These alternative specifications did not alter our results.
} 
to move both within and out of the postal code area, and as there are more people per room (crowding), one is more likely to move either within or out of the area.

Does a High Share of Ethnic Minorities in a Neighborhood Lead to Different Moving Behavior by Ethnic Group?

Model 2 includes the first interaction: individual ethnicity by non-western minority postal code area composition. It allows us to assess the relation between residential mobility of various ethnic groups in areas varying in terms of ethnic composition. Confirming hypothesis 2, this second model shows that all non-western ethnic minorities are less likely than native Dutch to move out of postal code areas with a greater share of non-western ethnic minorities, although Caribbeans and the group of other non-western ethnic minorities show a higher likelihood than native Dutch of moving out of their neighborhoods in general. Turks and Caribbeans, on the other hand, show a greater tendency than native Dutch to move within their postal code area as the share of non-western ethnic minorities in the area increases, although Caribbeans, Turks and Moroccans show a lower likelihood of moving within their postal code areas in general. Perhaps, Turks and Caribbeans who move to improve their housing situation (for example, move to a larger home or change from renting to owning) do so within the neighborhood more frequently than others. These findings suggest that non-western minority neighborhood composition is important in explaining the moving behavior of different ethnic minority groups.

With Model 3 we investigate whether people with a higher income are more likely to move out of neighborhoods with greater shares of non-western ethnic minorities than people with a lower income, and whether there is a difference between native Dutch and non-western ethnic minorities in this respect. For this purpose, we added the interaction of socio-economic status of the individual and the share of non-western ethnic minorities in the postal code area. In this model we see, first of all, support for hypothesis 3a: people with a higher income do move out of postal code areas with a greater share of non-western ethnic minorities more frequently than people with a lower income, although a higher income generally affects moving out of a postal code area negatively. The opposite is true for moving within a neighborhood. Second, when controlling for this interaction, we see that non-western ethnic minorities are still estimated to move less frequently than native Dutch out of neighborhoods with greater shares of non-western ethnic minorities, and move more frequently than native Dutch within neighborhoods with greater shares of non-western ethnic minorities. This finding lends support to hypothesis $3 \mathrm{~b}$. We can conclude that it is the combination of individual ethnicity and individual socio-economic status with a neighborhood's ethnic composition that influences moving out of a neighborhood.

\section{Conclusion and Discussion}

In this paper we put forward three hypotheses on the combined influences of ethnicity at the individual and the neighborhood levels on moving within and from 
neighborhoods. Our first hypothesis, stating that the higher the percentage of ethnic minorities in a neighborhood, the more frequently people move out of that neighborhood, is confirmed by our findings. Our second hypothesis stated that native Dutch would show a 'white flight' away from ethnic minority areas, whereas non-western minorities would more likely move within such areas or not move at all. This hypothesis was also confirmed by our analysis. Hypotheses $3 \mathrm{a}$ and $3 \mathrm{~b}$ were related to the effect of income. Despite the fact that higher income groups show more moves out of neighborhoods with a greater share of non-western ethnic minorities than lower income groups, the difference between native Dutch on the one hand and minority groups on the other in moving out of neighborhoods with greater shares of ethnic minorities did not disappear after controlling for income. Apparently, not every ethnic group moves out of an area to the same extent when the share of non-western ethnic minorities in that area is high, even if its members have the financial means to do so. Just as Pais et al. (2009), we find evidence of a selective 'white flight' from such areas. This result puts into question the validity of the spatial assimilation theory. Apparently there are more explanations at play than only an individual's income. The main possible explanations are those derived from the place stratification model or the ethnic enclave model. But our data do not allow elaborating on these explanations.

It is also possible that we are dealing not so much with place stratification or ethnic enclave formation, but with immigrant avoidance in the sense of native Dutch avoiding non-western immigrants and their offspring. That would be just another expression of the basic dynamic underlying the ethnic segregation in Dutch cities, which is not so much an increasing orientation of ethnic minorities on cities but, rather, the continuous suburbanization of native Dutch (Burgers 2005). If that would be true, this would shed an interesting light on the long-time Dutch policy of combating residential segregation by ethnic status. Our analyses suggest an orientation of non-western migrants toward neighborhoods with a greater share of ethnic minorities, even when income is not limiting the options in terms of moving behavior of migrants. If spatial assimilation cannot explain the residential mobility patterns we found, we would then be confronted with a situation that flies in the face of the basic assumption of integration policies. This basic assumption is that when members of migrant communities improve their socio-economic position, they will prefer to live outside ethnically concentrated areas. But because the main focus of this article is on moving out of neighborhoods, we do not know to what extent native Dutch moving out of high ethnic minority concentration neighborhoods move to low concentration neighborhoods. That is why further research needs to be conducted on the direction of the moves people make out of concentration neighborhoods.

Acknowledgements We are grateful to the Dutch Ministry of Spatial Planning, Housing and the Environment (VROM) for providing the HRN 2006 dataset release 1.2 (urn:nbn:nl:ui:13-tcv-dug (Persistent Identifier)), and to Data Archiving and Networked Services (DANS) for the data distribution. We also thank the anonymous reviewers for their helpful comments.

Open Access This article is distributed under the terms of the Creative Commons Attribution Noncommercial License which permits any noncommercial use, distribution, and reproduction in any medium, provided the original author(s) and source are credited. 


\section{References}

Aalbers, M. B. (2006). Who's afraid of red, yellow and green? Geographies of redlining and exclusion in the Netherlands and Italy. Amsterdam: Amsterdam Institute for Metropolitan and International Development studies, University of Amsterdam.

Aalbers, M. B., \& Deurloo, R. (2003). Concentrated and condemned? Residential patterns of immigrants from industrial and non-industrial countries in Amsterdam. Housing, Theory and Society, 20(4), 197-208.

Alba, R. D., \& Logan, J. (1991). Variations on two themes: Racial and ethnic patterns in the attainment of suburban residence. Demography, 28, 431-453.

Alba, R. D., \& Logan, J. (1993). Minority proximity to whites in suburbs: An individual-level analysis of segregation. American Journal of Sociology, 98, 1388-1427.

Alba, R. D., Logan, J. R., Stults, B. J., Marzan, G., \& Zhang, W. (1999). Immigrant groups in the suburbs: A re-examination of suburbanization and spatial assimilation. American Sociological Review, 64(3), 646-660.

Bolt, G., \& Van Kempen, R. (2003). Escaping poverty neighbourhoods in the Netherlands. Housing, Theory and Society, 20(4), 209-222.

Burgers, J. (2005). Verhuisgedrag en Woonaspiraties van Minderheden: Gewoon Klasse. Een Reactie op Van der Zwaard. Sociologie, 1(4), 476-478.

Burgers, J., \& Van der Lugt, H. (2006). Spatial assimilation of minority groups. Journal of Housing and the Built Environment, 21, 127-139.

Card, D., Mas, A., \& Rothstein, J. (2008). Tipping and the dynamics of segregation. The Quarterly Journal of Economics, 123(1), 177-218.

Clark, W. A. V., Deurloo, M. C., \& Dieleman, F. M. (2000). Housing consumption and residential crowding in U.S. housing markets. Journal of Urban Affairs, 22, 49-63.

Cutler, D. M., \& Glaeser, E. L. (1997). Are ghettos good or bad? The Quarterly Journal of Economics, 112(3), 827-873.

Dagevos, J., \& Gijsberts, M. (2005). De Opkomst van een Allochtone Middenklasse in Nederland. In SCP, Hier en Daar Opklaringen (pp. 84-88). The Hague: SCP.

De Groot, C. (2004). Zwarte Vlucht. De (Sub)urbane Locatiekeuze van Klassieke Allochtonen in Amsterdam. The Hague: Ministry of Spatial Planning, Housing, and the Environment.

Deane, G. D. (1990). Mobility and adjustments: Paths to the resolution of residential stress. Demography, 27, 65-79.

Fernandez, L., Howard, C., \& Amastae, J. (2007). Education, race/ethnicity and out-migration from a border city. Population Research and Policy Review, 26, 103-124.

Galster, G. C. (1991). Black suburbanization: Has it changed the relative location of races? Urban Affairs Quarterly, 26(4), 621-628.

Gowricharn, R. S. (2001). Ethnic minorities and elite formation. Journal of International Migration and Integration, 2(2), 155-167.

Gowricharn, R. S. (2003). De Emancipatie van Hindostanen. In C. E. S. Choenni \& K. Sh. Adhin (Eds.), Van Brits Indisch Immigrant via Suriname tot Burger van Nederland (pp. 90-105). The Hague: Sampreshan.

Gross, A. B., \& Massey, D. S. (1991). Spatial assimilation models: A micro-macro comparison. Social Science Quarterly, 72(2), 347-360.

Harris, D. R. (2001). Why are Whites and Blacks averse to black neighbors? Social Science Research, 30, $100-116$.

Helderman, A. C., Van Ham, M., \& Mulder, C. H. (2006). Migration and home ownership. Tijdschrift voor Economische en Sociale Geografie, 97, 111-125.

Huber, P. J. (1967). The behavior of maximum likelihood estimates under nonstandard conditions. Proceedings of the fifth Berkeley Symposium on Mathematical Statistics and Probability (pp. 221233). Berkeley, CA: University of California Press.

Jego, C., \& Roehner, B. M. (2006). White flight or flight from poverty? Journal of Economic Interaction and Coordination, 1(1), 75-87.

Logan, J. R., \& Molotch, H. L. (1987). Urban fortunes: The political economy of place. Berkeley: University of California Press.

Logan, J. R., Alba, R. D., \& Leung, S. (1996). Minority access to White suburbs: A multiregional comparison. Social Forces, 74, 851-881. 
Massey, D. S. (1985). Ethnic residential segregation: A theoretical synthesis and empirical review. Sociology and Social Research, 69(3), 315-350.

Massey, D. S., \& Denton, N. A. (1985). Spatial assimilation as a socioeconomic outcome. American Sociological Review, 50, 94-106.

Massey, D. S., \& Mullan, B. P. (1984). Processes of Hispanic and Black spatial assimilation. American Journal of Sociology, 89, 836-873.

McHugh, K. E., Gober, P., \& Reid, N. (1990). Determinants of short- and long-term mobility expectation for home owners and renters. Demography, 27, 81-95.

Mieszkowski, P., \& Mills, E. S. (1993). The causes of metropolitan suburbanization. The Journal of Economic Perspectives, 7(3), 135-147.

Ministry of Spatial Planning, Housing, and the Environment (VROM) (2006). Housing Research Netherlands 2006 (WoON 2006: Woon Onderzoek Nederland), release 1.2 urn:nbn:nl:ui:13-tcv-dug, Persistent Identifier. The Hague: Ministry of Spatial Planning and the Environment.

Mulder, C. H. (1993). Migration dynamics: A life course approach. Amsterdam: Thesis Publishers.

Pais, J. F., South, S. J., \& Crowder, K. (2009). White flight revisited: A multiethnic perspective on neighborhood out-migration. Population Research and Policy Review, 28(3), 321-346.

Palen, J. J. (1995). The suburbs. New York: McGraw-Hill.

Portes, A., \& Jensen, L. (1987). What's an ethnic enclave? The case for conceptual clarity. American Sociological Review, 52, 768-771.

Quillian, L. (2003). How long are exposures to poor neighborhoods? The long-term dynamics of entry and exit from poor neighborhoods. Population Research and Policy Review, 22, 221-249.

Rossi, P. H. (1955). Why families move. Glencoe, IL: The Free Press.

Schneider, M., \& Phelan, T. (1993). Black suburbanization in the 198d. Demography, 30(2), $269-279$.

South, S. J., \& Crowder, K. D. (1997a). Escaping distressed neighborhoods: Individual, community, and metropolitan influences. American Journal of Sociology, 102, 1040-1084.

South, S. J., \& Crowder, K. D. (1997b). Residential mobility between cities and suburbs: Race, suburbanization, and back-to-the-city moves. Demography, 34(4), 525-538.

South, S. J., \& Crowder, K. D. (1998). Leaving the hood: Residential mobility between Black, White, and integrated neighborhoods. American Sociological Review, 63(1), 17-26.

Speare, A. (1974). Residential satisfaction as an intervening variable in residential mobility. Demography, 11, 173-188.

Uitermark, J., \& Duyvendak, J. W. (2004). De Weg naar Sociale Insluiting, Over Segregatie, Spreiding en Sociaal Kapitaal. The Hague: RMO.

Uyterlinde, M., Van Arum, S., Engbersen, R., Lub, V., Schaake, K. (2007). Kiezen voor de Stad. Kwalitatief Onderzoek naar de Vestigingsmotieven van de Allochtone Middenklasse. Den Haag: Ministry of Spatial Planning, Housing, and the Environment.

Van der Horst, H., \& Wassenberg, F. (2004). De Wijk als Onderdeel van de Nederlandse Samenleving. Demografische en Maatschappelijke Ontwikkelingen. Inspiratiepapers Woonwijken van de Toekomst, Deel 2 (pp. 7-21). Delft: OTB/Habiforum.

Van der Zwaard, J. (2005). De Nederlanders achterna? Twijfels van Allochtone Sociale Stijgers Over Verhuizen Naar 'Een Betere Buurt'. Sociologie, 1(4), 463-475.

Van Huis, M., \& Nicolaas, H. (2000). Binnenlands Verhuisgedrag van Allochtonen. Maandstatistiek van de Bevolking, 48(3), 36-45.

Van Niekerk, M. (2000). De Krekel en de Mier. Fabels en Feiten over Maatschappelijke Stijging van Creoolse en Hindoestaanse Surinamers in Nederland. Amsterdam: Het Spinhuis.

Wilson, W. J. (1987). The truly disadvantaged. Chicago: University Of Chicago Press.

Wilson, W. J. (1996). When work disappears. The world of the new urban poor. New York: Alfred A. Knopf Inc.

Zhou, M., \& Logan, J. R. (1991). In and out of Chinatown: Residential mobility and segregation of New York city's Chinese. Social Forces, 70(2), 387-407.

Zorlu, A., \& Mulder, C. H. (2008). Initial and subsequent location choices of immigrants to the Netherlands. Regional Studies, 42(2), 245-264. 